\title{
Como Escrever Notas de Alta e Cartas de Referenciação? Uma Perspetiva Simples mas Efetiva
}

\section{How to Write Discharge Notes and Referral Letters? A Simple but Effective Perspective}

\author{
João GAMA MARQUES $\triangle 1,2$ \\ Acta Med Port 2018 Apr;31(4):189-190 - https://doi.org/10.20344/amp.10304
}

Palavras-chave: Portugal; Sumários de Alta do Paciente Hospitalar; Transferência da Responsabilidade pelo Paciente

Keywords: Patient Discharge Summaries; Patient Handoff; Portugal

Quantas vezes o leitor já recebeu das mãos de um doente uma carta de referenciação ou uma nota de alta que para pouco ou nada Ihe serviu? Umas, tão curtas, falham por serem demasiado breves, contendo poucas linhas, por vezes com siglas ao alcance apenas de quem as escreveu. Outras, demasiado longas, pecam por excesso e prolongam-se por várias páginas em que uma linguagem hermética ou romanceada pouco ou nada ajuda a quem as recebe e tem que ler.

Em apenas 10 anos de prática clínica pudemos perceber que existem muitos estilos diferentes, quer ao nível do conteúdo, quer ao nível da forma. Por exemplo, em pleno século XXI ainda há colegas que insistem em escrever à mão ou seja, sem recurso ao computador, de forma que a informação clínica em pouco tempo vira obsoleta (mesmo para quem a escreveu!) de tão indecifrável que é. Quantas vezes não vimos já isso nas urgências ou em processos clínicos de arquivo? A título de exemplo podemos dizer que, no âmbito da nossa investigação, as notas de alta do tempo da inauguração do Hospital Júlio de Matos (cuidadosamente dactilografadas a duas cores na década de 1940!) são de mais fácil leitura e compreensão do que muitas equivalentes nossas contemporâneas (manuscritas à pressa há meia dúzia de anos).

Perante esta dificuldade fomos desenvolvendo, de forma intuitiva e pragmática, uma metodologia na escrita desses dois tipos de documento. Com a preocupação de nunca ocuparmos mais do que uma página, começámos a utilizar, por tentativa e erro, o botão 'relatórios' no software em que fazemos os registos no nosso hospital. Nunca mais do que uma página porque, na nossa fantasia, nenhum colega a quem nos dirigimos por escrito, teria tempo ou disponibilidade para ler mais do que uma página. Nalgumas situações a necessidade aguça o engenho e assim nos vimos obrigados a ser os mais sucintos e sintéticos, dentro do modesto domínio que temos da nossa língua.

Nas cartas de referenciação aproveitámos o facto da identificação e contactos do doente constarem como cabeçalho, para passarmos diretamente, no primeiro parágrafo, ao(s) diagnóstico(s) com o(s) código(s) CID10 da Organização Mundial de Saúde ${ }^{1}$; no segundo a terapêutica em curso (em Denominação Comum Internacional); no terceiro a lista de resultados de exames complementares de diagnósticos realizados. No quarto parágrafo geralmente deixamos uma sugestão ao colega ou entidade a quem se dirige o documento; ficando as despedidas e agradecimentos para o quinto e último parágrafo. Quanto ao nosso nome clínico, vinheta e número de ordem, esses também são impressos, no final, automaticamente e por defeito, pelo software utilizado, pelo que não têm que ser incluídos na informação escrita por nós.

Nas notas de alta tivemos a vida muito facilitada pelo template da nossa instituição, ao qual não podemos (nem queremos!) fugir, bem como pelas regras impostas pela Comissão para a Informatização Clínica do Ministério da Saúde, que tem feito um importante esforço no sentido de uniformizar os registos realizados pelos profissionais de saúde nos vários centros hospitalares. ${ }^{2}$ Neste caso é importante não esquecer o pequeno grande pormenor de ter o cuidado de carregar o(s) diagnóstico(s) da OMS, por enquanto ainda em código $\mathrm{CID} 9,{ }^{3}$ antes de mandar imprimir o documento. O colega que receber a informação clínica agradece, e o colega codificador de diagnósticos da instituição também!

Seguindo ambos os modelos à risca temos conseguido alguns elogios de colegas, dentro e fora da especialidade, quer às nossas Cartas de Referenciação quer às nossas Notas de Alta, pela sua simples mas efetiva utilidade na transmissão da informação clínica entre instituições, de uma forma que se quer rápida, económica, ecológica, sem perder de vista a diminuição da probabilidade do erro médico. Este feedback positivo tem-nos deixado satisfeitos e trouxe-nos até, imaginem, à escrita deste artigo de perspetiva.

Claro está que estes nossos modelos não serão uma panaceia. Todos estamos limitados pelo software que usamos bem como por outros fatores mais ou menos idiossincráticos à especialidade ou à instituição em que trabalhamos. De qualquer forma temos que tomar consciência da importância deste assunto, que há anos que já é

\footnotetext{
1. Hospital Júlio de Matos. Centro Hospitalar Psiquiátrico de Lisboa. Lisboa. Portugal.

2. Clínica Universitária de Psiquiatria e Psicologia Médica. Faculdade de Medicina. Universidade de Lisboa. Lisboa. Portugal.

$\square$ Autor correspondente: João Gama Marques. joaogamamarques@gmail.com

Recebido: 28 de janeiro de 2018 - Aceite: 02 de fevereiro de 2018 | Copyright @ Ordem dos Médicos 2018
} 
Tabela 1 - Sugestão de estrutura para Cartas de Referenciação e Notas de Alta

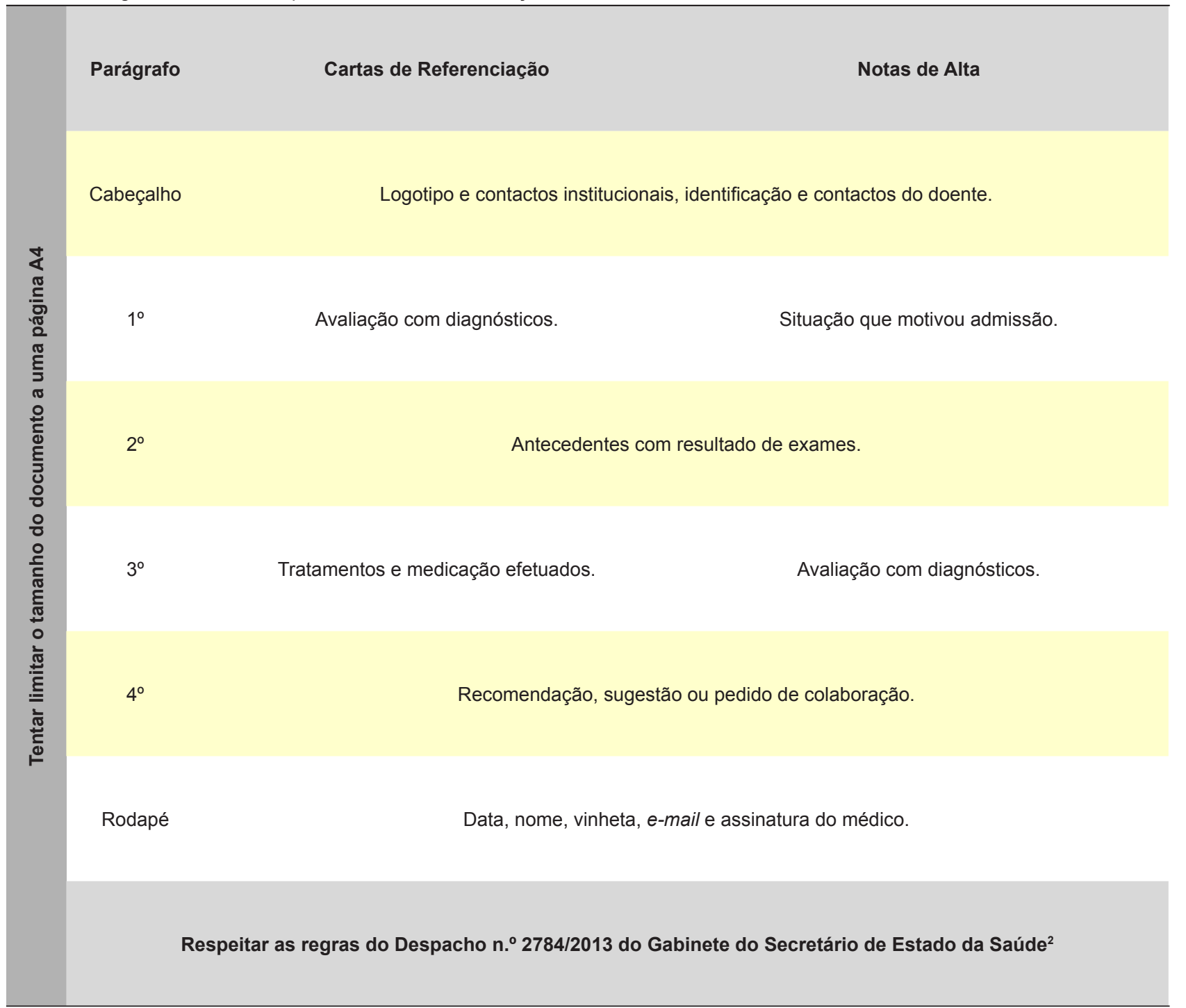

discutido noutros países, conforme uma breve pesquisa na PubMed nos permitiu perceber.

A Tabela 1 pretende sintetizar a nossa sugestão de estrutura para Cartas de Referenciação e Notas de Alta.

Finalmente, sabemos que o tempo é sempre pouco, mas não poderíamos deixar de terminar esta nossa perspetiva sem recomendar dois pequenos artigos, que poderão ajudar os colegas leitores a encontrar os seus próprios modelos. No caso da cartas de referência propomos a Structured Printed Referral Letter ${ }^{4}$ e no caso das notas de alta sugerimos a Situation-Background-Assessment-Recommendation. ${ }^{5}$

\section{REFERÊNCIAS}

1. World Health Organization. International Classification of Diseases. $10^{\text {th }}$ ed. [consultado 2018 jan 28]. Disponível em: http://apps.who.int/ classifications/icd10/browse/2010/en.

2. Gabinete do Secretário de Estado da Saúde. Despacho n. ${ }^{\circ} 2784 / 2013$. In Diário da República. [consultado 2018 jan 28]. Disponível em: https:// dre.pt/application/dir/pdf2sdip/2013/02/036000000/0690806909.pdf.

3. World Health Organization. International Classification of Diseases. $9^{\text {th }}$ ed. [consultado 2018 jan 28]. Disponível em: http://icd9cm.chrisendres. com/index.php?action=contents.

4. Ramanayake RP. Structured printed referral letter (form letter); saves time and improves communication. J Family Med Prim Care. 2013:2:145-8.

5. Lenert LA, Sakaguchi FH, Weir CR. Rethinking the discharge summary a focus on handoff communication. Acad Med. 2014;89:393-8. 